\title{
DESAFIOS DO JUDICIÁRIO E OS CONTRATOS DE CONCESSÃO DE AEROPORTOS: O TEMA DAS RECEITAS TARIFÁRIAS
}

\section{Resumo}

O presente artigo analisa as relações jurídicas envolvidas na importação, guarda e armazenagem de mercadorias importadas que ganharam significativa relevância ante a concessão de serviços aeroportuários. A discussão de tributos incidentes na importação pelo e o Estado pode, por vezes, gerar efeitos na esfera patrimonial dos concessionários. Propõe-se assim revelar o contexto destas relações e suas diversas implicações.

\begin{abstract}
This article analyzes the legal relationships involved in the import, storage and storage of imported goods that have gained significant importance at the concession of airport services. The discussion of taxes on imports by the taxpayer and the state can sometimes generate effects on the equity sphere of the concessionaire. It is proposed to reveal the context of those relations and its different implications.
\end{abstract}

Palavras-chave: Tarifas. Concessão de aeroportos. Tutelas jurisdicionais. Liberação de mercadorias importadas.

Keywords: Fares. Aiport concession. Jurisdictional protection. Release of imported goods.

\section{José Renato Camilotti}

Advogado e Consultor Jurídico. Doutorando, Mestre e Especialista em Direito Tributário pela PUC-SP. Professor conferencista do Instituto Brasileiro de Estudos Tributários (IBET). Professor convidado e palestrante em diversos cursos de pós-graduação em Direito Tributário. Juiz Contribuinte do Tribunal de Impostos e Taxas de São Paulo - TIT/SP (2014/2015).

\section{Danilo da Fonseca Crotti}


Advogado e Consultor Jurídico. Especialista em Direito Tributário pelo Instituto Brasileiro de Estudos Tributários (IBET). Pós-graduando em Direito Tributário pelo Instituto de Ensino e Pesquisa (INSPER). Juiz Contribuinte da Junta de Recursos Tributários de Campinas-SP (JRT).

\section{Introdução}

O exercício da jurisdição impõe a adequação das decisões exaradas pelo Poder Judiciário à satisfação das necessidades de seus tutelados, segundo os paradigmas das normas jurídicas aplicáveis às situações analisadas. O Estado-Juiz, ao manejar o sistema jurídico lidando com as demandas cotidianas, deve-se ater ao contexto das relações jurídicas havidas no bojo dos casos concretos postos sob seu crivo, aplicando as normas adequadamente aos fatos que lhes são trazidos, no clássico ritmo da incidência jurídica. Este trabalho é perene e incessante. Movimenta-se na cadência da evolução das normas e na evolução das relações sociais.

Nesse espeque, frutificam as demandas no Judiciário entre contribuintes e Fazenda Pública ${ }^{1}$ cujo objeto sejam decisões que, pelas mais variadas teses e motivos, buscam o desembaraço aduaneiro e internalização na economia pátria de mercadorias e produtos sem o pagamento das exações tributárias que nosso sistema prevê devidos nas operações de importação, v. g., o imposto de importação (II), o imposto sobre produtos industrializados (IPI), o imposto sobre a circulação de mercadorias e serviços (ICMS) etc.

Com esse introito, é tempo de aqui objetivar nosso foco de análise: queremos atenção para um novel desafio ao qual vem sendo chamado o Poder Judiciário, qual seja, de responder com decisões eficientes e congruentes com o sistema jurídico brasileiro às relações havidas entre os aeroportos

\footnotetext{
${ }^{1}$ Utilizamos aqui os termos "contribuinte" e "Fazenda Pública" como denotativos de sujeitos passivo e ativo de relações tributárias de índole material e/ou processuais.
}

http://revistasapereaude.org/index.php/edicoes/ano-5-volume-1-agosto-2016 
brasileiros e seus usuários, em função de que, hodiernamente, tenhamos na administração e operação de tais aeroportos, sociedades empresárias de capital privado (aeroportos concessionados).

Com o fito de maior delimitação do objeto de nossas considerações, analisaremos especificamente as relações jurídicas havidas entre os aeroportos concessionados e os seus usuários, cujos objetos sejam a remuneração dos serviços de armazenagem e capatazia prestados pelos primeiros aos últimos, quando as decisões do Poder Judiciário tutelam interesses do contribuinte, permitindo-lhe a retirada de mercadorias e produtos sem pagamento de quaisquer tributos.

\section{Ainda a questão da taxa $\mathbf{x}$ tarifa}

Sem pretensões outras que não a de delimitação do tema proposto, insta-se expor, ainda que em breves linhas, as já tão difundidas distinções entre as taxas e as tarifas, dado que são dois institutos jurídicos que possuem poucas semelhanças e marcantes diferenças. As semelhanças se limitam a característica de que ambas as categorias são remuneratórias pela prestação de serviços que sejam específicos e divisíveis, podendo ser prestados pelo próprio Estado ou quem por ele autorizado.

As diferenças, entretanto, revelam-se à mais branda luz, destacando-se a primeira delas pelo fato de que os usuários que pagam tarifa (ou preço público²) efetivamente utilizam-se dos serviços prestados ( $v \cdot g$. tarifa de ônibus), enquanto que os usuários podem ser onerados por taxas pelo simples

\footnotetext{
${ }^{2}$ Alguns autores utilizam como sinônimos as expressões tarifa e preço público. Vide, por exemplo, parecer do Prof. Ives Gandra da Silva Martins intitulado "Taxa de Controle e Fiscalização Ambiental-TCFA Constitucionalidade de sua Instituição". Disponível por Revista Jurídica da Presidência: https://revistajuridica.presidencia.gov.br/index.php/saj/issue/view/101 . Acesso em: 08/06/2016.
} 
fato do serviço ser colocado à sua disposição (quando obrigatórios) ou pela mera existência da estrutura administrativa que exercita o poder de polícia (v.g. taxa de fiscalização ambiental).

Ao depois, observa-se em grau de adição, que a taxa respeita o regime jurídico (regras e princípios, em uma possível distinção classificatória) do Direito Público, dentre eles, em especial os princípios do direito tributário, tais como a legalidade, a anterioridade, etc. Por outro lado, a tarifa tem substrato de regência no Direito Privado, mesmo quando cobrada pelo Estado, dado que está sob a batuta das regras de um contrato, em que o usuário só estará obrigado a contraprestação do pagamento quando efetivamente utilizar do serviço.

Portanto, conclui-se que taxa e tarifa (preço público) não são sinônimos, mas, sim, institutos jurídicos naturalmente distintos, não podendo ser confundidos pelo interprete jurídico, sob pena de seu estudo recair em grave erro hermenêutico.

Em parecer para tratar da legalidade da cobrança de taxa ambiental, o jurista Ives Gandra da Silva Martins ${ }^{3}$ traz a distinção entre o referido tributo e a tarifa (ou preço público, como denominado pelo ilustre Professor):

“Em Simpósio Nacional de Direito Tributário, que coordenei e que foi aberto pelo eminente Ministro José Carlos Moreira Alves, tendo como tema os conceitos de taxa e de preço público, o plenário declarou que:

' $1^{\text {a }}$ Questão: Em nosso ordenamento positivo, há critério jurídico para distinguir as taxas dos preços públicos? Em caso afirmativo, qual?

\footnotetext{
${ }^{3}$ Op. cit.
} 
Resposta: Sim. As taxas remuneram os serviços públicos. Demais serviços que não têm tal natureza serão remunerados por preço, chamados públicos, por serem cobrados pelo Poder Público, direta ou indiretamente.

São serviços públicos aqueles inerentes ao Estado, denominados essenciais, além daqueles cuja atividade econômica não compete originariamente à iniciativa privada (art. $8^{\circ}, \mathrm{XV}$ da $\left.\mathrm{CF}\right)$, dependendo da disciplina legal.

Atividade monopolizada não possibilita a cobrança de taxa, assim como a atividade econômica prevista no art. 170 da C.F.', sem excluir conformação mais abrangente por mim exposta nos seguintes termos:

'As taxas são tributos vinculados a uma atuação estatal, expressiva de serviço público prestado ou posto à disposição dos administradores, a cargo de entidades governamentais investidas de personalidade jurídica de direito público.

Os preços são receitas expressivas de serviços públicos prestados ou posto à disposição dos administrados, a cargo de entidades governamentais ou não governamentais investidas de personalidade de direito privado.

No ordenamento legal brasileiro há critério jurídico para distinguir as Taxas de Preços Públicos, a partir da exigência:

a) de relação de subordinação no primeiro tipo de remuneração e não no segundo;

b) de não possuir o usuário alternativa de não utilização ou de não pagamento para as taxas e possuir tal faculdade aos preços públicos; 
c) de ser a taxa remuneratória de serviços essenciais ou periféricos específicos e divisíveis, só o sendo o preço público, em não ocorrendo as hipóteses enunciadas nos itens "a" e "b"'.

E a Suprema Corte parece ter se orientado, na linha de minha proposta, ao considerar que as "taxas judiciais" não seriam "preços públicos", visto que faltaria "alternativa válida" para o usuário do Poder Judiciário, visto que a Constituição proíbe que se faça justiça com as próprias mãos.

A falta de alternativa válida, levou o Supremo Tribunal Federal a considerar que as custas judiciais não seriam preços públicos, como defendido pelo Judiciário de São Paulo - fui o autor da representação à Procuradoria Geral da República, em nome da OAB-SP -, mas taxas.

No referido Simpósio, defendi, inclusive, que a própria taxa pelo exercício do poder de polícia destina-se a remunerar serviço que beneficia seu pagador, nada obstante tal benefício ser indireto e não direto, como ocorre nas taxas por serviços públicos específicos e divisíveis.

Escrevi, para o Simpósio, o seguinte:

'O exercício do poder de polícia "lato sensu" é um serviço público prestado pelo ente tributante, a quem é facultado ressarcir-se pela espécie tributária denominada "taxa".

Tal ressarcimento vincula-se ao custo operacional do serviço prestado, em face de cobrança superior ao mesmo, embora de difícil quantificação, implicar imposição de espécie tributária diversa da rotulada de "taxa", eventualmente não enquadrável na competência residual da União para criar impostos. 
O serviço público, portanto, correspondente ao exercício do poder de polícia, é daqueles que só podem ser remunerados por tributo, o que vale dizer, a sua instituição deve ser revestida de todos os pré-requisitos indicados pelo sistema tributário nacional. Isto porque o tributo se acoberta, no país, das características de norma de rejeição social, impondo a Carta Magna que, pela lei, seja o sujeito passivo de sua relação protegido contra as tentações fiscalistas dos Erários, às voltas permanentemente com "déficits" públicos incontornáveis.

Outro tipo de serviço público remunerado pelas taxas vincula-se a benefício efetivo e potencial para seu usuário, o que vale dizer, vincula-se à natureza de serviços já discrimináveis "stricto sensu" e em relação direta com o contribuinte.

No serviço público de exercício do poder de polícia, seu grande beneficiário não é só o sujeito passivo, mas a coletividade, embora, indiretamente, o sujeito passivo também o seja. No serviço público de oferta de um bem material ou imaterial para utilização efetiva ou potencial pelo sujeito passivo, o grande beneficiário é o sujeito passivo e apenas, decorrencialmente, a comunidade'."

Parcela da doutrina nacional indica que o fator fundamental para identificar se um serviço público é remunerado por taxa ou tarifa seria por meio do agente que está encarregado pela prestação do serviço, sendo que o primeiro se relaciona com a Administração Pública e o segundo está ligado as pessoas jurídicas de direito privado, em regra, concessionárias de serviços público.

Contudo, ambos os institutos, taxa e tarifa, podem ser objeto de remuneração da prestação de serviço público feita tanto pelo Estado quanto de uma concessionária, pois o que os distingue não 
está no agente que presta o serviço, mas, cremos, na natureza da relação que lastreia o serviço e, por consequência, no regime jurídico a que ele se insere.

Se verificarmos a existência de uma relação contratual, em que há a possibilidade ou não de aderir ao contrato, independentemente de quem esteja no polo passivo da relação, o serviço será remunerado por tarifa, independentemente de quem seja seu prestador.

Entretanto, caso haja a caráter compulsório na de aceitação do serviço posto à disposição do usuário, mesmo que este não o utilize, o serviço será remunerado por taxa, uma vez que a relação jurídica aqui é regida pelo regime jurídico de direito público.

\subsection{Natureza jurídica da tarifa de armazenagem}

Analisando-se as recentes concessões da operação de alguns aeroportos à administração da iniciativa privada, um fenômeno tem se verificado nos contratos celebrados entre o poder concedente e as concessionárias, na parte que trata da descrição de receitas e remunerações, a saber, a possibilidade de se cobrar dos usuários dos aeroportos a denominada "taxa de armazenagem" pelo uso de seu espaço físico para a guarda de produtos e mercadorias.

Não obstante na maioria dos contratos de concessões constar graficamente a palavra "taxa", para a correta identificação da natureza jurídica desta obrigação, oportuno esmiuçar as características do serviço prestado pela concessionária de serviço público, para que então, estejamos habilitados a confirmar se a denominada "taxa" é realmente uma taxa, stricto senso, ou se trata de uma tarifa"

\footnotetext{
${ }^{4}$ Como ensinado nos comezinhos do Direito Tributário, a denominação gráfica de tributo não é fator relevante para a sua identificação. Vide disposto no art. $4^{\circ}$ do Código Tributário Nacional: "Art. $4^{\circ}$ A natureza jurídica específica do tributo é 
A "taxa de armazenagem", como dito, compõe a receita das concessionárias oriunda da contraprestação de serviços correlatos, como, por exemplo, guarda de produtos importados ou que aguardam liberação para exportação, encargos estes estabelecidos no contexto do contrato de concessão de prestação de serviços públicos para administração dos aeroportos concedidos à iniciativa privada.

Portanto, em um primeiro momento, já é possível observar que a “taxa de armazenagem” só será devida pelo usuário do aeroporto se houver efetivamente a prestação do serviço de guarda de produtos pela concessionária. Caso o usuário opte por utilizar outro modal de transporte para a importação de seu produto e/ou mercadoria, como o rodoviário ou o aquaviário (quanto possíveis), ou mesmo o marítimo, claro está que a cobrança da aludida "taxa" não será devida, e haverá a impossibilidade de sua cobrança pelas concessionárias dos aeroportos.

Tomando os ensinamentos expostos no tópico anterior, tratando-se de remuneração devida pela prestação de um serviço público, concedida à iniciativa privada, sem a característica de obrigatoriedade da contraprestação do serviço, concluir-se-á que a "taxa de armazenagem" é, na verdade, uma tarifa exigida das concessionárias de seus usuários, decorrente de um contrato de guarda e armazenagem de mercadorias, quando o usuário opta pela utilização do modal de transporte aéreo de determinado aeroporto.

A natureza de tarifa (ou preço público) da "taxa de armazenagem e capatazia" é, desde há muito, mesmo antes das recentes concessões dos aeroportos, reconhecido na jurisprudência dos Tribunais Superiores, sendo exemplos as decisões exaradas, pelo Superior Tribunal de Justiça (STJ) e Tribunais Regionais Federais (TRFs):

determinada pelo fato gerador da respectiva obrigação, sendo irrelevantes para qualificá-la: I - a denominação e demais características formais adotadas pela lei; II - a destinação legal do produto da sua arrecadação.” 
“TRIBUTÁRIO. TAXA DE ARMAZENAGEM AEROPORTUÁRIA. PRELIMINARES REJEITADAS. NATUREZA JURÍDICA. LEI N. 6.009

DE 26/12/73. LEGALIDADE. ADICIONAL DE TARIFA AEROPORTUÁRIA. LEI N. 7920 DE 12/12/89. NATUREZA JURÍDICA. LEGALIDADE.

I - REJEITO AS PRELIMINARES.

II - A TARIFA DE ARMAZENAGEM AEROPORTUÁRIA NÃO REPRESENTA UMA EXAÇÃO TRIBUTÁRIA, E TAMBÉM NÃO ESTÁ SUJEITA ÀS REGRAS QUE NORTEIAM O SISTEMA TRIBUTÁRIO, DENTRE AS QUAIS, AQUELAS QUE REGEM AS ALTERAÇÕES DE BASES DE CÁLCULO.

III - A LEI N. $\quad 6.009$ DE 26.12.1.973 INSTITUIU A TARIFA DE ARMAZENAGEM E CAPATAZIA DISPONDO SOBRE A UTILIZAÇÃO E EXPLORAÇÃO DOS AEROPORTOS, DAS FACILIDADES DE NAVEGAÇÃO AÉREA E OUTRAS PROVIDÊNCIAS.

IV - É PERFEITAMENTE POSSÍVEL A COBRANÇA DA TARIFA DE ARMAZENAGEM E CAPATAZIA PELA IMPETRADA, VEZ QUE HÁ PREVISÃO LEGAL PARA A EXIGÊNCIA DESSE ENCARGO.

V - MISTER SE FAZ ASSEVERAR QUE CABE A COBRANÇA DA TARIFA DA ARMAZENAGEM AO IMPETRANTE, VEZ QUE NÃO CONSTA NOS AUTOS PROVA DA INEXISTENNCIA DA GUARDA E DO ARMAZENAMENTO DAS SUAS MERCADORIAS NOS ARMAZÉNS DE CARGA AÉREA DO AEROPORTO.

VI - O ADICIONAL DE TARIFA AEROPORTUÁRIA, FOI CRIADA PELA LEI N.7.920, DE 12.12.1989, O ADICIONAL NADA MAIS E DO QUE UM AUMENTO NO VALOR DA TARIFA DE QUE TRATA A LEI 6.009/73, POIS TEM DETERMINAÇÃO INDÊNTICA A DA TARIFA AEROPORTUÁRIA SENDO QUE TODO O PRODUTO DA ARRECADAÇÃO DA TARIFA E DO ADICIONAL SE CONCENTRA EM QUEM PRESTA OS SERVIÇOS REMUNERADOS, E ESSA CIRCUNSTÂNCIA AFASTA A ALEGAÇÃO DE QUE SE TRATA DE IMPOSTO. MESMA NATUREZA JURÍDICA DA TAXA.

VII - NÃO HÁ INCONSTITUCIONALIDADE NO TOCANTE À INSTITUIÇÃO, ASSIM COMO À COBRANÇA DOS ENCARGOS QUESTIONADOS NOS AUTOS, NÃO ESTANDO ENTÃO CONFIGURADA A LESÃO AO DIREITO LÍQUIDO E CERTO DO IMPETRANTE. VIII - REMESSA OFICIAL E APELAÇÃO PROVIDAS PARCIALMENTE.

(Apelação em MS n.115945, Rel. Des. Fed. CECÍLIA MARCONDES, Terceira Turma do TRF3, DJ de 21/07/1999)

“TRIBUTÁRIO - TAXA DE ARMAZENAGEM PORTUÁRIA - PREÇO PÚBLICO LIBERAÇÃO DE CARGAS - TAXA DE URGÊNCIA - DECRETO 24.508/34 E 24.511/34 - RESOLUÇÃO 136/89 - SERVIÇOS EXTRAORDINÁRIOS NÃO ACOBERTADOS PELA CAPATAZIA.

1. À facultatividade da taxa afasta-se a sua natureza tributária, para situá-la como preço público. 
2. Serviço de descarga privilegiado pela urgência não acobertado pela taxa de capatazia.

3. Possibilidade de criação de taxa diferenciada por portaria, nos termos do art. 13 do Decreto 24.511/34.

4. Honorários advocatícios que, para serem majorados, demandariam exame de prova, coibido nesta instância especial (Súmula 07/STJ).

5. Recursos especiais conhecidos e improvidos."

(REsp 419.141/SP, Rel. Ministra ELIANA CALMON, Segunda Turma STJ, julgado em 16/05/2002, DJ 02/12/2002, p. 287)

\section{“TRIBUTÁRIO E PROCESSUAL. RECURSO ESPECIAL TAP. PREÇO PÚBLICO. JURISPRUDÊNCIA PACIFICADA. SÚMULA 83/STJ.}

1. "A "Taxa de Armazenagem Portuária", por tratar-se de preço público, a despeito de sua denominação, não está sujeita aos princípios que regem a relação jurídico-tributária. Assim sendo, é legítima sua fixação por meio de portaria ministerial, sem que isso represente qualquer ofensa ao princípio da legalidade" (REsp 115.783/SP, Rel. Min. João Otávio de Noronha)

2. "Não se conhece de recurso especial pela divergência, quando a orientação do Tribunal se firmou no mesmo sentido da decisão recorrida" (Súmula 83/STJ).

3. Recurso especial não conhecido."

(REsp 205241/SP, Rel. Ministro CASTRO MEIRA, Segunda Turma STJ, julgado em 01/03/2005, DJ 09/05/2009)

“TRIBUTÁRIO. TAXA DE ARMAZENAGEM PORTUÁRIA. PREÇO PÚBLICO. ALTERAÇÃO DO IMPOSTO DE IMPORTAÇÃO. INOCORRÊNCIA. PORTARIA N ${ }^{\circ}$ 10, DE 27.01.92 DO MINISTÉRIO DA INFRA-ESTRUTURA. LEGALIDADE.

Tarifa portuária, também denominada de "taxa de armazenagem" constitui preço público e não tributo (taxa), não sofrendo as mesmas restrições que incidem sobre este. Precedentes do STJ. Não houve alteração do Imposto de Importação, mas adoção de novo sistema para o cálculo do valor da taxa de armazenagem portuária, quando a alíquota do Imposto de Importação correspondente for inferior a 50\%. Competência do Ministro dos Transportes para fixar os períodos normais e subsequentes de armazenagem interna de mercadorias, bem como os percentuais sobre elas incidentes. Inteligência da Súmula $n^{\circ}$ 148 do STF. Apelação improvida."

(Apelação Civel 0203615-94.1992.4.03.6104, Quarta Turma TRF3, Rel. Juiz Convocado PAULO SARNO, DJe 29/11/2010)

\section{"ADMINISTRATIVO - MANDADO DE SEGURANÇA - TAXA DE ARMAZENAGEM PORTUÁRIA - LEGALIDADE}

A taxa é um tributo que tem, na hipótese de incidência, uma atividade estatal, direta e especificadamente dirigida ao contribuinte, se subdividindo em um serviço público e outras em razão do exercício do poder de polícia. Tarifa, no entanto, é o meio pelo qual se paga por um serviço facultativo. Trata-se de uma prestação contratual voluntária. $\mathrm{O}$ 
Poder Público se serve da cobrança por meio de preço ou tarifa pela prestação de um serviço público voluntário. Este tipo de atividade não se encontra acobertada pelos princípios constitucionais tributários, afastando - se, inclusive, o disposto no artigo 145, inciso II, da carta Magna. Precedentes. Pela análise da Lei n. ${ }^{\circ}$ 6.009/73, figura-se devida a tarifa de armazenagem apenas nos casos de efetiva utilização do serviço portuário. Apelação não provida."

(Apelação Civel 0025550-16.1997.4.03.6100, Terceira Turma TRF3, Rel. Des. Federal NERY JUNIOR, DJe 26/04/2010)

\begin{abstract}
ADMINISTRATIVO - TARIFAS AEROPORTUÁRIAS E PREÇOS PÚBLICOS PREVISTAS NA LEI N ${ }^{\circ} 6.009 / 73$ - ADICIONAL DE TARIFAS AEROPORTUÁRIAS PREVISTO NA LEI No $7.920 / 89$ - CONSTITUCIONALIDADE - NATUREZA JURÍDICA QUE NÃO SE CONFUNDE COM TRIBUTO - FÓRMULA DE CÁLCULO DAS COBRANÇAS - DISCRICIONARIEDADE DA ADMINISTRAÇÃO - I - São constitucionais as cobranças de Tarifa de Armazenagem (prevista na Lei ${ }^{\circ}$ 6.009/73) e o Adicional de Tarifa Aeroportuária (previsto na Lei $\mathrm{n}^{\circ}$ 7.920/89), afastando-se as alegações de que tratariam de tributo. Precedentes do Eg. STF (ex. RE 323444). II - As tarifas aeroportuárias possuem natureza jurídica de contrapartida por serviços prestados, afastando-se alegações de natureza de imposto. Precedentes do Eg. STJ (ex. REsp 86132/RS e REsp 86.474/RS) III - As fórmulas de cálculo das cobranças previstas nas Leis $n^{\circ}$ 6.009/73 e 7.920/89 utilizam critérios administrativos, em relação aos quais não cabe ao Judiciário substituir. IV - Remessa necessária e apelações da União Federal e da INFRAERO providas e apelação dos Autores não provida. (Apelação Cível/Reexame Necessário $\mathrm{n}^{\circ}$ 0020420-23.2001.4.02.5101, Relator Des. SERGIO SCHWAITZER, Sétima Turma Especializada TRF2, , julgado em 27/04/2016)
\end{abstract}

Em esforço analítico sobre os julgados supracitados, verifica-se que as tarifas, enquanto receitas operacionais das administradoras dos aeroportos, são objeto de estrita regulamentação e normatização, não havendo ampla liberdade econômica de seu administrador para alteração, dado que são totalmente vinculadas à política tarifária da Agência Nacional de Aviação Civil - ANAC.

O estabelecimento da política tarifária, por sua vez, leva em conta a modicidade tarifária para a menor oneração do usuário do serviço público, de forma que a equação tarifa (enquanto receita) permita a boa prestação e manutenção dos serviços concedidos.

Esse entendimento não apenas se mantém após as concessões dos aeroportos à iniciativa privada, como adquire especial relevância às sociedades empresarias administradoras dos aeroportos, vez que a contraprestação da "taxa de armazenagem” pelos usuários de seu espaço físico torna-se 
uma de suas principais fontes de remuneração lastreadas no contrato de concessão e que, ao fundo, permitirão a viabilização de todas as obrigações havidas no bojo dos contratos administrativos de concessão.

A afirmação acima pode ser verificada em recente decisão proferida pela Desembargadora Federal Diva Malerbi, da $6^{\text {a }}$ Turma do Tribunal Regional Federal da $3^{\text {a }}$ Região, que, apreciando a natureza da "taxa de armazenagem" cobrada da concessionária Aeroportos Brasil Viracopos S/A, recém empossada como administradora do Aeroporto Internacional de Viracopos, na cidade de Campinas/SP, define que os valores exigidos não podem ser confundidos com tributo, vez que nitidamente está caracterizado como preço público. Vide conteúdo da decisão:

\section{"DECISÃO}

Trata-se de agravo de instrumento interposto por COMIC STORE COML/ LTDA. contra decisão que, em mandado de segurança, reconsiderou a decisão de fls. 510 na qual determinava a Aeroportos Brasil Viracopos S/A - ABV a liberação das mercadorias identificadas na DI $n^{\circ}$ 03/0414404-0, sem o pagamento da taxa de armazenagem, "devendo a impetrante se socorrer das vias próprias para a liberação do pagamento que entende indevido ou mesmo para que a responsabilidade do ato, eventualmente, recaia sobre a União Federal".

Sustenta o agravante, em síntese, que o v. acórdão proferido nos autos do mandado de segurança em questão, concedeu a segurança para o efeito de determinar a liberação imediata das mercadorias apreendidas, independente do pagamento dos tributos apurados, ou da prestação de garantia. Aduz que a r. decisão agravada ao condicionar a liberação das mercadorias, já decidida de forma soberana e definitiva pelo E. Tribunal, à satisfação de uma taxa de armazenagem, a que a agravante não deu causa, retira-se indevidamente àquela decisão superior a eficácia que lhe é inerente. Afirma que quem deve responder pela taxa de armazenagem é a própria autoridade fiscal, a União Federal.

Requer o provimento do presente agravo, "a fim de que seja determinada a pronta liberação das mercadorias identificadas na Declaração de Importação $n^{\circ}$ 03/04144040 , a perfazer-se nestes próprios autos, sem que para esta finalidade seja a agravante compelida a satisfazer a taxa de armazenagem, uma vez que, diante do quanto ocorrido no curso dos autos, não pode ela ser responsabilizada pelo pagamento da indigitada taxa".

\section{Decido.}

Cabível na espécie o art. 557 do Código de Processo Civil.

Tal dispositivo, na redação dada pela Lei n ${ }^{\circ}$ 9.756, de 17 de dezembro de 1998, trouxe inovações ao sistema recursal, com a finalidade de permitir maior celeridade à tramitação 
dos feitos, autorizando o relator, por meio de decisão monocrática, a negar seguimento a recurso manifestamente inadmissível, improcedente, prejudicado ou em confronto com súmula ou jurisprudência dominante do respectivo tribunal, do Supremo Tribunal Federal, ou de Tribunal Superior. O seu $\S 1^{\circ}$ também faculta ao relator, desde logo, dar provimento ao recurso, se a decisão recorrida for manifestamente contrária a súmula ou jurisprudência dominante do STF ou de Tribunal Superior.

Da análise dos documentos juntados aos autos, verifica-se que a ora agravante impetrou mandado de segurança contra ato do Sr. Inspetor da Receita Federal junto ao Aeroporto Internacional de Viracopos - Campinas/SP, objetivando a liberação da mercadoria importada, de sua propriedade, independente do recolhimento dos tributos apurados em procedimento fiscalizatório.

Pela r. decisão monocrática, proferida nos termos do art. 557, § $1^{\circ}$-A, foi dado parcial provimento à apelação da impetrante, para reformar a sentença e conceder a segurança em parte, "apenas para determinar a liberação imediata das mercadorias apreendidas, independente do pagamento dos tributos apurados, ou da prestação de garantia" (fls. 111/113).

Com efeito, a taxa de armazenagem tem natureza jurídica de preço público e não de tributo. A taxa de armazenagem é verdadeira contraprestação de serviços prestados pela companhia de armazenagem, aos que deles se utilizam.

Nesse sentido, precedentes do C. Superior Tribunal de Justiça:

\section{TRIBUTÁRIO. ADICIONAL DE TARIFA AEROPORTUÁRIA. LEI No 7.920/89. LEI} $N^{\circ} 6.009 / 73$.

1. O Adicional de Tarifa Aeroportuária representa apenas e tão-somente um acréscimo ou um plus à já existente Tarifa Aeroportuária.

2. O Adicional de Tarifa Aeroportuária e as Tarifas Aeroportuárias têm a mesma destinação. Tendo a mesma destinação e tratando-se de um acréscimo à tarifa já existente, não se pode atribuir ao adicional a natureza de imposto, já que foi mantida a natureza jurídica de contrapartida pelos serviços prestados.

3. Recurso especial improvido.

(REsp 86.132/RS, Rel. Ministro CASTRO MEIRA, SEGUNDA TURMA, julgado em 19/08/2004, DJ 27/09/2004, p. 283)

\section{ADMINISTRATIVO - MANDADO DE SEGURANCA - TARIFA AEROPORTUÁRIA - ISONOMIA.}

1. A utilização de áreas e espaços nos aeroportos é remunerada pelo pagamento de uma taxa, criada por lei (Lei 6.009/73) e fixada por Portaria do Ministério da Aeronáutica, ou por preço cobrado das instituições que exploram a utilização dos espaços chamados civis dos aeroportos, hoje sob a égide da INFRAERO.

2. No pagamento das tarifas aeroportuárias, deve-se obedecer ao critério do serviço que é utilizado pelo contribuinte ou posto à sua disposição.

3. Empresa que se utiliza de áreas da zona primária e, eventualmente, de áreas da zona secundária, sofre enquadramento mais oneroso que as empresas que só se utilizam de uma das áreas.

4. Segurança denegada. 
(MS 8.060/DF, Rel. Ministra ELIANA CALMON, PRIMEIRA SEÇÃO, julgado em 28/08/2002, DJ 25/11/2002, p. 178)

TRIBUTARIO. TAXA DE ARMAZENAGEM. PREÇO PUBLICO. IMPORTAÇ̃̃O.

1. NÃO OFENDE AO ORDENAMENTO JURIDICO PORTARIA EXPEDIDA PELO MINISTERIO DOS TRANSPORTES QUE ELEVA O VALOR DO PREÇO PUBLICO REFERENTE A ARMAZENAGEM DE MERCADORIA IMPORTADA.

2. A ARMAZENAGEM E PREÇO PUBLICO. NÃO HA QUE CONFUNDIR A SUA EXIGENCIA COM TAXA. AQUELE NÃO E COMPULSORIO E CORRESPONDE A UMA REMUNERAÇÃO PELOS SERVIÇOS VOLUNTARIAMENTE PROCURADOS.

3. PRECEDENTES JURISPRUDENCIAIS.

4. RECURSO ESPECIAL IMPROVIDO.

(REsp 156.459/SP, Rel. Ministro JOSÉ DELGADO, PRIMEIRA TURMA, julgado em 10/03/1998, DJ 27/04/1998, p. 103)

Assim, embora usualmente conhecida como 'taxa de armazenagem', a sua natureza jurídica não se amolda ao gênero tributo, nem tampouco à espécie taxa, pois de preço público se cuida.

Portanto, não cabe ao agravante realizar interpretação extensiva do v. acórdão, com o fito de extrair o entendimento no sentido de que a "taxa de armazenagem" estaria a integrar a vedação estabelecida pelo julgado quanto à cobrança de tributo.

Exsurge, dessa forma, que não há violação aos termos do v. acórdão proferido às fls. $361 / 364$.

Como bem assinalado na r. decisão agravada:

"Assiste razão à Aeroportos Brasil Viracopos S/A, pois na r. decisão de fls. 351/353 não há dúvida quanto à liberação somente do pagamento dos tributos, não havendo possibilidade de liberar-se a mercadoria sem o pagamento da taxa de armazenagem, visto que esta, na realidade, é tarifa a ser cobrada de acordo com determinadas tabelas, pelas mercadorias importadas.

Assim, respeitosamente reconsidero o despacho de fl. 510 devendo à impetrante se socorrer das vias próprias para a liberação do pagamento que entende indevido ou mesmo para que a responsabilidade do ato, eventualmente, recaia sobre a União Federal."

Ante o exposto, com fulcro no artigo 557, caput, do Código de Processo Civil, nego seguimento ao agravo de instrumento."

(AGRAVO DE INSTRUMENTO $\mathrm{N}^{\circ}$ 0002815-86.2016.4.03.0000/SP, Relatora a Desembargadora Federal DIVA MALERBI, $6^{\mathbf{a}}$ Turma do Tribunal Regional Federal da $3^{\mathrm{a}}$ Região)

Diante do cenário acima delineado, resta claro que a "taxa de armazenagem" é receita que remunera a concessionária de serviço público em decorrência de relação jurídica de direito privado, 
advinda do contrato de concessão, sendo componente essencial na equação do equilíbrio econômicofinanceiro da empresa privada encarregada de operar o aeroporto.

Portanto, demonstrada a natureza jurídica de tarifa da denominada "taxa de armazenagem" prevista nos contratos de concessões dos aeroportos nacionais para regular a relação jurídica de direito privado entre as concessionárias e seus usuários, caberá ao interprete jurídico, quando do processo hermenêutico para compreensão do tema, ab initio, excluir de seu corte metodológico qualquer relação entre os princípios e regras do direito tributário e os princípios e regras do direito privado e administrativo que regem a relação jurídica entre as concessionárias e seus usuários, sob pena de invalidar todo o raciocínio lógico-jurídico.

\section{O setor econômico na operação dos Aeroportos Brasileiros}

Após o reestabelecimento do regime civil no Brasil tem-se buscado cada vez mais reduzir o encargo estatal com atividades de interesse geral. Tal panorama que inicialmente havia sido em parte repelido pela Constituinte de 1988 acabou por tomar forma na Lei $\mathrm{n}^{\circ} 8.987 / 95$.

Tal veículo normativo determinou o regime jurídico aplicável às concessões de serviços públicos, com vistas à ampliação dos direitos e garantias das concessionárias, relativizando-se a supremacia do interesse público.

Como dito, as concessionárias dos aeroportos são pessoas jurídicas de direito privado, via de regra, sociedades anônimas regidas pela Lei n. 6.404/76 - Lei das Sociedades Anônimas. Ao mesmo tempo, também são sociedade de propósito específico (SPE) constituída para o único e exclusivo fim 
de realizar a prestação de serviços públicos de ampliação, manutenção e exploração da infraestrutura aeroportuária do Aeroporto Internacional de Viracopos, por expressa previsão dos contratos de concessão celebrados entre os particulares e a ANAC, com fundamento no disposto do art. 21, XII, “c” da Carta da República5.

Observa-se adicionalmente, que nos contratos de concessões, e neste espeque, na interação havida no contexto da armazenagem e movimentação de cargas no aeroporto, a relação que se estabelece é exclusivamente entre os usuários dos serviços prestados e os operadores/administradores de um dado aeroporto, os quais, presentemente para nosso objetivo, são sempre uma pessoa jurídica de direito privado concessionária de serviços.

Não há, necessário que assim se o diga, no contexto do desenvolvimento dos serviços prestados pelas concessionárias operadoras dos aeroportos, qualquer influência, ingerência ou relação com a União relativamente à relações jurídicas de natureza tributária.

A própria regulamentação e normatização das tarifas cobradas pelo uso dos serviços prestados pelas concessionária dos aeroportos são fixadas pela ANAC e compõem o bojo de receitas (da espécie tarifárias) dos contratos de concessão. Não há elo de ligação entre essas receitas tarifárias e a arrecadação de tributos por parte da União ou qualquer outro ente federativo, em função da importação de mercadorias/ou produtos por parte dos usuários dos aeroportos.

Repise-se, os contratos de concessão para administração e operação dos aeroportos preveem basicamente duas fontes de custeio de todas as obrigações que lhe são impostas nas cláusulas do contrato administrativo: as receitas tarifárias e as receitas não tributárias.

\footnotetext{
${ }^{5}$ Constituição Federal: “Art. 21. Compete à União: (...) XII - explorar, diretamente ou mediante autorização, concessão ou permissão: (...) c) a navegação aérea, aeroespacial e a infraestrutura aeroportuária;” 
As receitas tarifárias são constituídas, como a própria nomenclatura indica, pelas tarifas previstas nos contratos de concessões, condicionadas à regulamentação pela ANAC, e são devidas às concessionárias pelos usuários quando de efetiva utilização dos serviços, dos equipamentos, das instalações e das facilidades disponíveis nos aeroportos, dentre eles, como já tratado anteriormente, as tarifas de armazenagem e de capatazia.

Por sua vez, as receitas não tarifárias são constituídas, a contrário senso, por todas as receitas das concessionárias que não oriundas de tarifas. Em síntese, tratam-se de receitas pela exploração do espaço físico do aeroporto para outros fins, que não a prestação de serviço ao usuário, por exemplo, aluguel de espaço para lojas de comércio, cobrança de estacionamento de veículos, etc.

Importante destacar que em ambos os casos estaremos diante de receitas contratuais, advindas da exploração da concessão de serviço público, expondo a nítida relação jurídica de direito privado.

\section{A nova realidade das relações jurídicas}

Delineadas em linhas sumulares as principais características da natureza jurídica das concessões de aeroportos e da remuneração pela contraprestação dos serviços prestados pelas concessionárias deste serviço público, oportuno traçar paralelo entre três relações jurídicas absolutamente distintas, porém que causam rotineira dúvida do interprete jurídico quando instado a se manifestar sobre a legalidade e validade da "taxa de armazenagem", são elas: (i) a relação jurídica de direito administrativo entre o Estado e a concessionária do serviço público; (ii) a relação jurídica de direito privado entre a concessionária e seus usuários, e; por fim, (iii) a relação jurídica de direito tributário entre o Estado e os contribuintes, pela incidência das normas de natureza tributária nas 
operações de importação e exportação por meio do transporte aéreo, v.g., como já dito, o IPI, o II, o ICMS, etc.

Se o contexto ora tratado for analisadas da maneira segregada e razoável, como de fato impinge a racionalidade das diferentes situações e suas consequências, facilmente se constata a independência incondicional entre as três relações jurídicas supracitadas, cada qual com a peculiaridade do ramo do direito a que pertence, seus sujeitos de direito, seus deveres e obrigações.

Para revelar a distinção hialina, tomamos como exemplo uma operação de importação de produtos realizada por uma pessoa jurídica de direito privado, através de um aeroporto concedido à iniciativa privada, na qual o Estado, por meio do órgão administrativo de fiscalização competente, determina a retenção das mercadorias por ausência ou recolhimento a menor dos tributos devidos na operação, por quaisquer motivos que sejam.

Nesta situação identifica-se as citadas três relações jurídicas: (i) a relação jurídica de índole administrativa entre o Estado e a concessionária do serviço público, por meio da qual foi concedida à iniciativa privada a administração e gestão do aeroporto, mediante a expectativa de determinação remuneração, composta por receitas tarifárias e não tarifárias, ambas de natureza de direito privado, como exposto anteriormente; (ii) a relação jurídica de direito privado entre a concessionária e seus usuários, por meio da qual a concessionária exige o pagamento de remuneração pelos serviços prestados, como por exemplo, a guarda e armazenagem de mercadorias importadas, as quais ocupando espaços nos armazéns que são cedidos mediante contraprestação financeira, não podem deixar de ser remunerados, e; por fim, (iii) a relação jurídica de natureza tributária entre o Estado e o contribuinte, por meio da qual o Estado compulsoriamente exige do contribuinte os tributos que entende devidos em determinada operação, e, ainda, em razão de qualquer discussão acerca de tal relação imponha a retenção das mercadorias em recinto alfandegado, que, no caso, é de administração da concessionária do aeroporto. 
Há, assim, nas diversas relações, os seguintes sujeitos de direito: na relação (i), Estado (União) X Concessionária; na relação (ii), Concessionária X Usuário, e; na relação (iii) Estado (União, Estados, Distrito Federal e Municípios) x usuário (contribuinte).

No espeque do exemplo acima, imagine que o contribuinte, não satisfeito com a exigência tributária do Estado, ingresse com determinada ação judicial visando assegurar que não seja onerado pela imposição estatal (tributo); e mais, não seja apresentado pelo contribuinte nenhum tipo de garantia prevista em lei para a imediata liberação das mercadorias, tais como, depósito do valor das mercadorias, seguro garantia, carta fiança, etc.

De se notar que a irresignação do contribuinte volta-se única e exclusivamente contra o Estado-arrecadador, indiscutivelmente uma relação jurídico tributária entre o sujeito ativo e o sujeito passivo da obrigação tributária. Contudo, por uma conduta ativa ou omissiva da pessoa jurídicacontribuinte, que deixa de apresentar algum tipo de garantia prevista em lei para a imediata liberação das mercadorias, observa-se que é afetada outra relação jurídica absolutamente distinta da relação jurídico tributária entre o contribuinte e o Estado, qual seja, a relação jurídica de direito privado entre a pessoa jurídica que importou a mercadoria e a pessoa jurídica concessionária do aeroporto, vez que esta disponibiliza seu espaço para guarda e armazenamento, responsabiliza-se por sua segurança e, eventualmente, movimenta, para melhor acondicionamento, justamente das mercadorias e/ou produtos que estão dentro da propriedade que administra.

Se somarmos a esse contexto, a consideração de que eventuais discussões que envolvem relação jurídico tributária entre contribuintes e o Estado podem durar anos, perante o Poder Judiciário, tem-se que a concessionária do aeroporto pode ser obrigada a guardar, armazenar e fornecer segurança às mercadorias importadas pelo contribuinte, durante todo o período que durar o processo, em função de opção exclusiva deste, por não apresentar a devida garantia para a imediata liberação 
das mercadorias importadas. E, ainda, sequer pode a concessionária do aeroporto intervir na discussão envolvendo o contribuinte e o Estado, pois não é parte legitima na relação jurídico tributária.

Em situações deste jaez, as quais podem perdurar em anos de discussão judicial envolvendo contribuinte e o Estado acerca da exigência tributária, podem ter desfecho em que o Poder Judiciário reconheça o direito do contribuinte em não se sujeitar ao pagamento do tributo exigido pelo Estado (total ou parcialmente), seja qual seja a fundamentação da decisão.

À toda evidência, é de se considerar à margem de tal discussão, por decorrência lógica e jurídica, a demanda em que causa de pedir e pedido envolvam e tenham natureza tributária, e a relação obviamente de índole privada que vincule o importador das mercadorias (usuário dos serviços prestados pelo aeroporto) e a própria concessionária.

Em desfecho possível, como no exemplo acima em que a demanda sobre a inexigibilidade do tributo seja vencida pelo contribuinte, restará a importadora/usuário se dirigir à administração da concessionária do aeroporto e solicitar a retirada das mercadorias armazenadas em sua propriedade, sem a necessidade de comprovar o recolhimento dos tributos exigidos pelo Estado, vez que possuirá decisão judicial com transito em julgado a seu favor.

A concessionária, por sua vez, se verá obrigada a realizar os procedimentos de liberação sem qualquer exibição da prova do recolhimentos das obrigações de natureza tributária, em função da decisão judicial que lhe seja apresentada. Nada obsta e nada pode obstar, porém, que seja cumprida a obrigação de índole privada, de remunerar mediante a aludida "taxa de armazenagem", devida à concessionária em função da guarda e depósito dos produtos e mercadorias, advinda do contrato firmado entre as partes quando do início da operação de importação.

Reitera-se que a permanência das mercadorias no estabelecimento da concessionária tem dois prismas de análise: (i) a causa da retenção se deu no centro de uma demanda tributária entre Estado 
X Contribuinte, e; (ii) a opção de não fornecer garantia para a liberação da mercadoria é ato sujeito à exclusiva opção do contribuinte

Não se afeta em qualquer caso a relação jurídica de natureza privada, da espécie de prestação de serviços, havida entre o Concessionária X Usuário, pela cessão do espaço, armazenagem, e guarda das mercadorias e produtos do usuário, e que deve ser remunerada pela tarifa de armazenagem e capatazia, a qual, por sua vez, é receita tarifária que compõe a equação de equilíbrio contratual entre a concessionária e União, e que permite viabilizar o modelo de concessão e administração privada dos aeroportos.

No contexto fático aqui proposto é indubitável a constatação da existência das relações jurídicas de (i) direito privado entre importador e a concessionária do aeroporto, (ii) índole administrativa entre a concessionária e o Estado, além da (iii) de natureza tributária entre o contribuinte e o Estado. Todas as relações jurídicas são autônomas e independentes entre si.

Nota-se, ainda, que eventual propositura de demanda judicial entre os sujeitos ativo e passivo da relação jurídico-tributária não possui qualquer pertinência ou relação com as demais relações jurídicas anteriormente mencionadas. Logo, eventual decisão judicial favorável ao contribuinte para se eximir do recolhimento de tributos exigidos pelo Estado, não torna indevida a exigência da tarifa de armazenagem oriunda da relação jurídica de direito privado entre a pessoa jurídica importadora e a concessionária responsável pela guarda e segurança das mercadorias.

Cotejada a autonomia e distinção das relações jurídicas que podem envolver uma simples operação de importação, como acima exemplificado, verifica-se que a identificação dos conceitos jurídicos e bem assim do regime a serem aplicados a cada relação jurídica pode não ser a tarefa mais fácil diante da análise de um caso concreto e apresenta-se como um desafio ao Poder Judiciário. 
É de se ver que na tentativa de desoneração total na importação de mercadorias, o usuário/importador quer se eximir do pagamento da tarifa de armazenagem devida à concessionária, alegando, em suma, que não foi ele quem deu causa à demora e ao armazenamento, atribuindo a culpe ao Estado-fisco.

Nesse caminhar, não é incomum os importadores usuários ajuizarem ações judiciais em face das concessionárias de serviço público (administradoras dos aeroportos) ou até mesmo provocar o Poder Judiciário na ação em que se discutiu a relação jurídico tributária, pleiteando o não pagamento da aqui aludida tarifa, muitas vezes sob o argumento de inexistência de relação jurídica com a concessionária.

A nova realidade das concessões da operação e administração dos aeroportos exige atenção ao contexto das relações jurídicas havidas entre Estado X Concessionária X Usuário (contribuinte).

A incompreensão ou incorreção de percepção dessa novel realidade, na maioria das vezes, pode ser debitada ao, por assim dizer, vício de enxergar na operação de administração dos aeroportos a União, ou ainda, outras pessoas jurídicas de direito público da administração indireta a ela vinculadas, como no exemplo, a INFRAERO (Empresa brasileira de infraestrutura aeroportuária).

Não é mais possível que assim seja. As concessões de aeroportos à iniciativa privada tem supedâneo em um contrato que prevê margem de lucro na operação. A lucratividade, com modicidade tarifária é pedra de toque e alicerce do modelo de concessão de aeroportos. As tarifas de armazenagem e capatazia são parte integrante do rol de receitas tarifárias que sustentam o modelo de concessão, com previsão expressa nos contratos administrativos de concessão.

Como noticiado alhures, as tarifas pela prestação e serviços (no caso em testilha, a de armazenagem e capatazia) são devidas em caráter de remuneração por serviços prestados e que representam custo para as concessionária. Compõem, assim, a equação de equilíbrio econômico- 
financeiro do contrato de concessão e não podem ser simplesmente ignoradas no contexto das demandas havidas entre Estado X Contribuintes (usuários).

As tarifas aqui aludidas são objeto de uma relação jurídica de direito privado com natureza de prestação de serviço, suportada e lastreada pelo Direito Regulatório Aeroportuário e respectivo contrato de concessão, que tem como esteio e pressuposto a organização e logística das relações de transito aduaneiro.

A origem da retenção dos produtos/mercadorias no armazém, causa direta da existência dos custos de armazenagem e lastro para a cobrança de tarifas de armazenagem e capatazia, envolvem única e exclusivamente a conduta do importador, quando não se dispõe a efetivar garantia para a liberação de mercadoria ou do Estado-fisco, quando exige o cumprimento de deveres ou obrigações tributárias que ao depois se mostrarão indevidas, mas, jamais tal imputação deve ser dirigida à concessionária que administra o aeroporto.

A concessionária não participa de eventual discussão acerca da relação jurídico tributária que tem como sujeito o Estado-fisco e o contribuinte, não dá causa às retenções de mercadorias no armazém, não influencia na perpetuação temporal do impasse, ou seja, é a única parte a qual não se pode cogitar de culpa, em quaisquer de suas dimensões ou conceitos jurídicos.

Eventual debate a ser inaugurado sobre a responsabilidade de quem deve arcar com os custos de armazenagem decorrentes de retenção promovida pelo Estado para exigir o pagamento de tributo, deve ser objeto de ação judicial própria, que envolva as partes e sujeitos próprios, os quais participaram em qualquer dimensão do suposto fato ilícito que tenha causado eventuais danos.

A natureza de tarifa pela prestação de serviços impõe a remuneração da concessionária pelo usuário do serviço. Eventual ação judicial a ser promovida pela pessoa jurídica importadora deve ser manejada contra o Estado-fisco, desta vez, não para discutir se o tributo é devido ou não, mas para 
discussão de eventual reparação civil (indenização) pelos custos incorridos pela pessoa jurídica importadora.

A concessionária não é parte legítima para figurar em ação judicial cujo objeto é a responsabilização ou não do Estado. O eventual reconhecimento de dano perpetrado pelo Estado à pessoa jurídica importadora, que corresponde ao valor da armazenagem, não faz transmudar a relação jurídica existente entre a pessoa jurídica importadora e a concessionária do aeroporto. Ao contrário, a referida situação apenas faz nascer uma outra, decorrente de eventual ilícito praticado pelo Estado, pela não liberação das mercadorias, e que deve ser reparada em ação própria, com pedido próprio, sem prejuízo de a empresa importadora honrar a relação de prestação de serviço que possui com a concessionária.

Reconhecer que a importadora possa simplesmente retirar a mercadoria sem o pagamento das tarifas de armazenagem é subtrair receita da concessionária sem que ela tenha cometido qualquer ilícito.

Ademais, sendo a tarifa de armazenagem um componente essencial das receitas do contrato de concessão e, por isto, elemento inerente ao equilíbrio econômico-financeiro de tal contrato, é admitir a possibilidade de subtração de resultados operacionais que tornam inviável o cumprimento do objeto contratado, colocando em risco a operação do aeroporto.

\section{Conclusões}

Dada a existência de relações jurídicas distintas entre importador x Estado, importador x concessionária e Estado x concessionária é imperativo que o Poder Judiciário ao se deparar com 
demandas relativas à liberação de mercadorias importadas observe o tratamento próprio da relação importador $\mathrm{x}$ concessionária.

Não obstante a condição eminentemente tributária discutida em tais demandas, toda e qualquer decisão judicial deve observar, obrigatoriamente, o regime próprio das concessões aeroportuárias.

Consoante o já aqui demonstrado a tarifa de armazenagem representa receita ordinária do concessionário, pela prestação direta de um serviço ao importador, qual seja, a guarda de mercadorias.

Questão de grande relevância surge com a demora de uma resposta do Poder Judiciário ao apelo do contribuinte que busca afastar a tributação à ele imposta pelo Estado quando da importação de mercadorias. Isso porquanto, ao passo contribuinte que opta por não apresentar garantia com vistas à liberação da mercadoria importada, esta permanecerá armazenada pela concessionária com todos os ônus incidentes à armazenagem. Tal relação perdurará até que seja decidida a questão tributária, o que sujeitará o importador ao pagamento da tarifa de armazenagem por todo o período.

Caberá ao Poder Judiciário delimitar objetivamente em suas decisões a abrangência de seus efeitos, pois o deslinde da relação importador x Fisco não deverá, automaticamente, influir na relação importador x concessionária. De tal sorte não poderá a decisão relativa à matéria tributária, da qual a concessionária não compõe a relação emanar seus efeitos à relação de guarda tida pelo importador e a concessionária, sendo necessária a distinção das relações pelo julgador quando da análise da demanda.

Com a nova sistemática de concessão dos serviços aeroportuárias deverá o julgador se ater à existência destas novas relações, posto que o que antes representava um conjunto de relações entre as mesmas partes, qual seja, importador e Estado, hoje contém um novo sujeito de direitos, com deveres e obrigações próprias para cada um dos sujeitos envolvidos na operação de importação. 
Estes são os necessários desafios a serem enfrentados nas tutelas a serem concedidas pelo Poder Judiciário, no contexto das demandas jacentes à importação e liberação de mercadorias em que haja a participação de um ente privado no processo de condução da mercadoria e armazenagem da mesma. O Estado-Juiz deve se postar ante tais desafios com todos os elementos da evolução das relações jurídicas aqui desveladas, de forma que a prestação jurisdicional, notadamente em demandas tributárias na liberação de mercadorias importadas por aeroportos concedidos, não violem direitos de terceiros em relação às demanda nas quais estes não sejam, e não possam ser, sequer protagonistas.

\section{REFERÊNCIAS BIBLIOGRÁFICAS}

AMARO, LUCIANO DA SILVA. Direito tributário Brasileiro. 10. ed. São Paulo: Editora Saraiva, 2004.

ATALIBA, Geraldo. Hipótese de incidência tributária. 6. ed. São Paulo: Malheiros, 2000. . Sistema constitucional tributário brasileiro. São Paulo: Revista dos Tribunais, 1966.

BECKER, Augusto Alfredo. Teoria Geral do Direito Tributário. 3. ed. São Paulo: Saraiva, 1998.

CARrAZZA, Roque Antonio. Curso de direito constitucional tributário. 18. ed. São Paulo: Malheiros, 2003.

CARVALHO, Aurora Tomazini de. Curso de teoria geral do direito: o constructivismo lógicosemântico. São Paulo: Noeses, 2009.

CARVALHO, Paulo de Barros. Direito tributário: linguagem e método. 3. ed. São Paulo: Noeses, 2009.

COSTA, Regina Helena. Curso de direito tributário - Constituição e Código Tributário Nacional. São Paulo: Saraiva, 2009.

MARTINS, Ives Gandra da Silva. Taxa de Controle e Fiscalização Ambiental-TCFA Constitucionalidade de sua Instituição. Disponível por Revista Jurídica da Presidência: https://revistajuridica.presidencia.gov.br/index.php/saj/issue/view/101 . Acesso em: 08/06/2016. 